(C) American Psychological Association, 2019. This paper is not the copy of record and may not exactly replicate the authoritative document published in the APA journal. Please do not copy or cite without author's permission. The final article is available, upon publication, at the following doi: $10.1037 / \mathrm{xge} 0000587$ 
Moral Essentialism and Generosity Among Children and Adults

\author{
Larisa Heiphetz ${ }^{\mathrm{a}}$ \\ ${ }^{a}$ Department of Psychology, Columbia University, 1190 Amsterdam Ave., New York, NY \\ 10027, United States. Email: lah2201@columbia.edu (Corresponding author)
}

Word count (main text + abstract): 9,964

In press at Journal of Experimental Psychology: General

Acknowledgements: The author wishes to thank Hannah Brody, Marianna Graziosi, Nina Mandracchia, Rachel Mulholland, Emily Nakkawita, Priya Reji, Ariel Rosario, Jillian Segarra, Michael Sosa, and Davida Vogel for their assistance with data collection and coding; James Dunlea, Colin Leach, and Redeate Wolle for their feedback on this manuscript; and Amanda Montoya for statistical advice. The research and ideas described here were presented at the 2017 meeting of the Society for Philosophy and Psychology and at the Science and Imagination of Living Generously workshops held in 2016 and 2017. A summary of this project is available on the Science and Imagination of Living Generously website:

https://blog.philanthropy.iupui.edu/2018/04/05/researching-generosity/. This work was supported by the Indiana University Lilly School of Philanthropy [grant \#INDU CU16-1919; re-granting program from the John Templeton Foundation], by grant \#61080 from the John Templeton Foundation, and by Columbia University's Provost's Grants Program for Junior Faculty who Contribute to the Diversity Goals of the University, all awarded to LH. These funding sources played no direct role in study design; in the collection, analysis, and interpretation of data; in the writing of the report; and in the decision to submit the article for publication. The opinions expressed in this publication are those of the author and do not necessarily reflect the views of the John Templeton Foundation. 


\begin{abstract}
Children and adults view many characteristics in an essentialist way — as innate, immutable, and biological. Prior work has typically investigated essentialism regarding broad domains (e.g., gender rather than maleness/femaleness). Using the example of morality, the current work asked whether individuals view different components of one domain (goodness/badness) differently and whether such views might influence behavior. Five- to eightyear-olds reported more essentialism than adults; however, both children and adults viewed goodness in more essentialist terms than badness. Although views of morally relevant characteristics in general did not significantly predict generosity (Study 1), essentialist views of the recipient did influence generosity (Studies 2-3). Adults shared fewer resources than would be expected by chance with people whose badness was described in essentialist terms (and consequently more resources than would be expected by chance with people whose badness was described in non-essentialist terms), an effect that did not appear to be driven by demand characteristics and that persisted even when both descriptions explicitly noted that the character would always remain bad. Although adults reported less essentialism than children, essentialist descriptions appeared to influence their behaviors more. This work highlights the need to investigate essentialism regarding specific domain components (e.g., goodness/badness) in addition to the domain overall (e.g., morality), partially because essentialism impacts behavior differently across components. Findings also suggest that emphasizing situational factors contributing to wrongdoing and a transgressor's ability to change may benefit people when they have committed moral violations.
\end{abstract}

Keywords: essentialism; generosity; morality; pro-social behavior; social cognitive development 


\section{Moral Essentialism and Generosity among Children and Adults}

The 1956 film The Bad Seed introduced viewers to Rhoda, a sweet-looking child who later drowned a classmate who had won a prize that Rhoda desired. Meanwhile, Rhoda's mother discovered that she was adopted and that her biological father, Rhoda's grandfather, was a serial killer. This information caused Rhoda's mother to worry that Rhoda's badness was inherited and unchangeable.

Although Rhoda's mother did not have the language of scientific psychology to describe her worry, her concern reflects essentialism - the notion that some characteristics arise from an internal, immutable essence that is rooted in biology (Gelman, 2003; Medin \& Ortony, 1989). These essences are perceived to be central to identity. For example, an essentialist view of Rhoda's badness posits that this moral quality makes Rhoda who she is and distinguishes her from other types of people (Haslam, Rothschild, \& Ernst, 2000; Heiphetz, Strohminger, \& Young, 2017). Such perceptions need not be accurate; indeed, in many cases, scientific evidence contradicts essentialist judgments (Leslie, 2013; Rhodes \& Mandalaywala, 2017). The question for psychologists is not whether such essences exist but whether people think they exist and, if so, what the consequences of these perceptions might be.

Using the framework of psychological essentialism, the current work asked three questions. First, to what extent do people view moral characteristics in essentialist terms? Second, what are the consequences of such essentialist perceptions? Third, how do patterns related to moral essentialism change or stay the same across development?

\section{To What Extent Do People View Moral Characteristics In Essentialist Terms?}

Past work on essentialism has typically focused on domains outside of morality, indicating that while both children and adults believe that essences exist, young children hold 
this view particularly strongly. For example, ten-year-olds and adults view behaviors that are stereotypically associated with gender as amenable to environmental influence (e.g., a girl who grows up surrounded by males can play with toy trucks), whereas younger children perceive less environmental influence, reporting that a girl who grows up surrounded by males will play with a tea set instead of trucks (Taylor, Rhodes, \& Gelman, 2009; for other evidence of age-related changes in essentialism, see Chalik, Leslie, \& Rhodes, 2017; Cimpian \& Steinberg, 2014; Diesendruck, Birnbaum, Deeb, \& Segall, 2013; Gelman, Heyman, \& Legare, 2007; Heiphetz, Gelman, \& Young, 2017; Heyman \& Gelman, 2000). Evidence of essentialism has emerged in a number of domains in addition to gender, including natural kinds (e.g., species), social groups (e.g., race), and psychological characteristics (e.g., beliefs; Brescoll \& LaFrance, 2004; DarNimrod \& Heine, 2011; Diesendruck et al., 2013; Gelman et al., 2007; Heiphetz, Gelman, \& Young, 2017; Kraus \& Keltner, 2013; Prentice \& Miller, 2006; Segall, Birnbaum, Deeb, \& Diesendruck, 2015; Sousa, Atran, \& Medin, 2002; Waxman, Medin, \& Ross, 2007; Williams \& Eberhardt, 2008).

Although past work has shown that participants view a wide array of categories as innate, immutable, and rooted in biology, the extent to which individuals believe these characterizations apply to morality is less clear. Addressing this topic makes two contributions to the study of essentialism. First, prior work has shown that moral characteristics are perceived as central to identity. For example, participants report that changes to moral characteristics would result in large changes to personal identity and that people would change more after morally relevant changes than after changes to other characteristics, such as preferences (Heiphetz, Strohminger, Gelman, \& Young, 2018; Heiphetz, Strohminger, \& Young, 2017; Strohminger \& Nichols, 2014). Participants further report a reluctance to accept organ transplants from people whose 
moral characteristics differ from their own, a finding that has been interpreted as showing that people perceive that an organ donor's essence would be transplanted along with his or her organ (Meyer, Leslie, Gelman, \& Stilwell, 2013). Identity centrality is one component of essentialism (Haslam et al., 2000; Heiphetz, Strohminger, \& Young, 2017); however, it is not clear whether judgments regarding morality show other trademarks of essentialist reasoning (e.g., the perception that the characteristic in question is immutable). Discovering the extent to which moral characteristics elicit additional components of essentialism would clarify the extent to which different components of essentialism cohere (e.g., whether a characteristic that is perceived to have one component of essentialism is also judged to have the other components as well).

Second, testing the domain of morality allows researchers to determine whether individuals may apply essentialist frameworks differently to different sub-categories within one domain. To date, the essentialism literature has largely focused on examining broad categories and has not elucidated potential differences among sub-categories. For example, people sometimes view race in essentialist terms (Jayaratne et al., 2006; Mandalaywala, RangerMurdock, Amodio, \& Rhodes, in press; Williams \& Eberhardt, 2008); however, few studies have examined whether participants may apply an essentialist framework to their understanding of Blackness more, or less, than to their understanding of Whiteness.

Despite this general trend, several studies have proven to be exceptions. For example, Haslam et al. (2000) highlighted the links between stigmatized sub-categories and essentialism. Of even greater relevance to the current work, Heyman and colleagues $(1998,2000)$ tested essentialism regarding both good and bad characteristics. However, conflicting predictions could be made on the basis of this past research: elementary-schoolers viewed good behaviors as more 
stable over time than bad behaviors (Heyman \& Dweck, 1998) but, in a separate study, reported that children would share the moral characteristics of their birth parent regardless of whether those characteristics were good or bad (Heyman \& Gelman, 2000). Further, this work did not probe the consequences of essentialist perceptions. The current research sought to provide additional evidence regarding the extent to which children might view goodness in more essentialist terms than badness and to test the behavioral consequences of moral essentialism.

Thus, one main contribution of the current work is investigating the extent to which individuals view goodness and badness as immutable and rooted in a biological source. People may view goodness in more essentialist terms than badness, a possibility consistent with work showing that adults perceive moral goodness to be a central component of their own and others' identities (De Freitas et al., 2018; Newman, Bloom, \& Knobe, 2014). Recall that essentialized characteristics are often perceived to be central to identity, rooted in biology, and unchanging (Gelman, 2003; Gelman et al., 2007; Haslam et al., 2000; Heiphetz, Strohminger, \& Young, 2017). If participants view goodness as more central to identity than badness, they may also view goodness in more essentialist terms than badness in other ways, by reporting that goodness is more likely to be biological and unchanging.

\section{What Are The Consequences Of Essentialist Perceptions?}

As discussed above, one contribution of the current work is determining the extent to which participants view goodness and badness in essentialist terms. A second contribution is investigating the consequences of essentialist views. In particular, the present work examined whether essentialism regarding morality might be associated with one's own moral behaviors, such as generosity. 
Conceptually, it is possible for essentialism to have positive consequences, such as increasing generosity. For example, participants who see themselves as innately good may wish to act in line with that perception, and participants who see others as innately good may behave more generously due to the perception that good characteristics are particularly good when they are innate rather than learned (Tsay \& Banaji, 2011). Indeed, some work highlights positive consequences of essentialism in the domain of sexual orientation; viewing this characteristic as unchanging and rooted in biology is associated with more favorable attitudes toward sexual minorities (Haslam \& Levy, 2006; Jayaratne et al., 2006). However, in most domains where researchers have studied the consequences of essentialism, the weight of the evidence points to negative consequences. Leading adults to adopt an essentialist view of gender increases their gender stereotyping (Brescoll \& LaFrance, 2004), and leading adults to adopt an essentialist view of race increases their acceptance of racial inequality (Williams \& Eberhardt, 2008; for additional evidence on the link between essentialism and racial attitudes, see Jayaratne et al., 2006; Mandalaywala, Amodio, \& Rhodes, 2018). Children, too, are affected by essentialist views. The extent to which they endorse racial essentialism predicts negative attitudes toward Black people, stronger endorsement of race-based stereotypes, and worse memory for racially ambiguous faces (Gaither et al., 2014; Mandalaywala et al., in press; Pauker, Apfelbaum, \& Ambady, 2010). Further, children who are led to view a fictional group in an essentialist way give fewer resources to members of that group than do children who are led to view that same group in a non-essentialist way (Rhodes, Leslie, Saunders, Dunham, \& Cimpian, 2018).

These prior studies have investigated the behavioral consequences of viewing entire domains (e.g., race) in essentialist terms. However, as described above, it is theoretically possible to apply an essentialist framework to different degrees even within one domain. In the 
moral domain, people may apply an essentialist framework to different extents when thinking about goodness versus badness. The current studies asked whether viewing goodness in essentialist terms leads to different outcomes than viewing badness in essentialist terms. For example, viewing badness in essentialist terms may lead to particularly low generosity. People may not want to share resources with inherently bad people, but they may be more willing to share with people who became bad due to circumstances beyond their control. To test this possibility, Study 1 examined the extent to which participants' essentialism predicted their generosity toward others, and Studies 2-3 manipulated essentialism to probe a potential causal mechanism.

In addition to asking whether participants' own essentialism predicted their own generosity, Study 1 also investigated whether participants' own essentialism predicted their expectations regarding others' generosity. For example, is it the case that participants who perceive others' goodness as innate and unchanging expect other people to behave more generously than participants who view others' goodness as socially learned and changeable? This possibility is consistent with work showing that adults perceive good characteristics as especially good when they stem from an internal source (Tsay \& Banaji, 2011). Because essentialist views of morality posit that moral characteristics stem from an internal "essence," participants who hold such views may expect "good" people to be even better (and thus behave more generously) than participants who hold less essentialist views of morality. Thus, viewing goodness in essentialist terms may be linked with the expectation that the good person will be particularly likely to engage in pro-social behavior, and the reverse may be true for essentialist views of badness. 
Alongside these theoretical contributions, probing the consequences of moral essentialism holds translational implications. Knowing the consequences of essentialist versus non-essentialist framings can be useful in interpersonal relationships, nearly all of which will involve some type of transgressions at one time or another. Imagine a common kindergarten scenario in which Carl, who is cranky and needs a nap, says something mean to Russell. Subsequently, Russell may be more willing to share his toys with Carl if he frames the earlier event in non-essentialist terms (e.g., "Carl didn't share with me because he needed a nap") rather than essentialist terms (e.g., "Something inside of Carl just makes him a bad person"). Further, Carl's ability to form social bonds with others in the class may be strengthened if the teacher describes the event in non-essentialist terms. If the teacher instead describes Carl as innately, unchangingly bad, he will likely face ostracism from his peers, perhaps leading him to say more mean things in the future.

It may be difficult to imagine any teacher describing a student as having a bad essence, at least if that teacher wants to keep her job. Yet essentialist explanations may arise more often in contexts involving more severe transgressions that can lead to the perception that the transgressor is a "bad person." Several non-profits seek to assist exactly these individuals; for example, Life After Hate helps people leave extremist hate groups, and Homeboy Industries assists people who have been incarcerated. Discovering the impact of essentialist versus nonessentialist messages regarding morality can help these groups effectively solicit charitable contributions. Learning the impact of essentialist versus non-essentialist framings can also elucidate the broader consequences of character-based labels and potentially inform efforts to change cultural narratives that highlight a transgressor's internal, unchanging badness.

\section{How Do Patterns Related To Moral Essentialism Change Or Stay The Same Across}


Development? As discussed above, the current research contributes to work on essentialism and moral cognition by testing the extent to which participants view goodness and badness in essentialist terms and by probing the behavioral consequences of moral essentialism. Another contribution of the current work is testing moral essentialism, and its behavioral consequences, among both children and adults.

One reason to compare children and adults is to determine the extent to which patterns regarding moral essentialism that are present in adults are also present during the elementary school years. One possibility outlined above is that participants may view goodness in more essentialist terms than badness because people's core identities are seen as morally good; for example, adults typically report that good behaviors reflect a person's "true self" and bad behaviors reflect a person's “surface self” (De Freitas et al., 2018; Newman et al., 2014). However, this "good true self" effect has only been documented among adults.

Of course, children may also perceive people as good. This possibility is consistent with past work showing that children report more optimistic evaluations of others than adults, although the measures in this work differ from those used in the literature on the "good true self" (e.g., elementary-schoolers require more instances of observing negative behaviors than do adults before attributing the relevant negative trait to individuals, Aloise, 1993; see also Alvarez, Ruble, \& Bolger, 2001; Boseovski \& Lee, 2006). Indeed, children more readily accept generics — grammatical forms that describe category-based generalizations — when they reference people's morally good, rather than bad, qualities (e.g., children are more likely to agree that "people are helpful" than that "people are dangerous," Tasimi, Gelman, Cimpian, \& Knobe, 2017). Because generic statements lead to essentialism (Rhodes, Leslie, \& Tworek, 2012), children may view goodness in more essentialist terms than badness. However, elementary- 
schoolers typically report more essentialism than adults (Cimpian \& Steinberg, 2014; Gelman et al., 2007; Heiphetz, Gelman, \& Young, 2017). Children's strong reliance on essentialist viewpoints may overwhelm any differences between goodness and badness, leading children to view all moral characteristics in highly essentialist terms.

A second reason to test children and adults in the same paradigm is that doing so allowed the present research to determine whether adults' pro-social behavior might be more sensitive to essentialism than children's pro-social behavior. Because adults are less likely than children to view characteristics in an essentialist way (Cimpian \& Steinberg, 2014; Gelman et al., 2007; Heiphetz, Gelman, \& Young, 2017), essentialist explanations may exert a particularly strong influence on their behavior. In other words, providing people with an explanation that matches a framework they themselves might have used may exert a relatively weak influence on behavior, whereas providing people with an explanation that changes how they themselves might have seen a situation may also change their behavior. Finding that adults' behaviors are more sensitive than children's behaviors to essentialist explanations, which highlight internal characteristics such as a person's biological make-up, would also be consistent with work showing that adults' judgments are more sensitive than children's judgments to information about a person's internal qualities (Cushman, Sheketoff, Wharton, \& Carey, 2013; Helwig, Zelazo, \& Wilson, 2001; Zelazo, Helwig, \& Lau, 1996). While this prior work highlighted the role of intention in moral judgment, it is possible that changes in the influence of one type of internal cue signal changes in how internal cues more broadly affect moral cognition and behavior.

\section{Overview of Current Research}

The current research investigated whether children and adults view goodness and badness in essentialist terms and probed the consequences of these essentialist perceptions. The present 
studies compared 5- to 8-year-old children and adults. Recruiting these age groups allowed for a test of two competing possibilities regarding essentialism. On the one hand, children of this age are optimistic about others (Aloise, 1993; Alvarez et al., 2001; Boseovski \& Lee, 2006) and may therefore report more essentialism regarding goodness than badness. On the other hand, elementary-schoolers readily report essentialist views regarding a number of social and natural categories, much more so than adults (Cimpian \& Steinberg, 2014; Gelman et al., 2007; Heiphetz, Gelman, \& Young, 2017). This strong reliance on essentialist frameworks may overwhelm any differences between goodness and badness, leading children to view all moral characteristics in highly essentialist terms. Comparing children and adults also clarifies whether the consequences of essentialism may differ across age.

An initial study (see Supplemental Materials) indicated that children and adults do view moral characteristics in an essentialist way to some extent, although this effect depends on participant age (children reported more essentialism than did adults) and characteristic valence (participants reported more essentialism regarding goodness than badness). In this initial study, participants' own essentialism did not predict their generosity. Study 1 sought to replicate these effects in a new sample and to investigate two additional variables: participants' perceptions regarding their own goodness (because participants may act in line with their own self-views) and participants' expectations regarding others' generosity (because participants may expect people who are innately, unchangingly good to behave particularly generously). Studies 2-3 asked whether essentialism regarding the morally relevant characteristics of a specific personrather than essentialism regarding morally relevant characteristics in general, as tested in Study 1 -influenced generosity toward that person.

\section{Study 1}


Study 1 was designed to address the three main questions outlined above. First, to what extent do people view moral characteristics in essentialist terms? To address this question, participants indicated the extent to which they perceived moral characteristics to be immutable and biological. Adults perceive that moral goodness is a central component of others' identities (De Freitas et al., 2018; Newman et al., 2014), and identity centrality is one component of essentialism (Haslam et al., 2000; Heiphetz, Strohminger, \& Young, 2017). Therefore, adults may be particularly likely to apply other components of essentialism to their view of goodness as well; in other words, they may view goodness as unchanging and rooted in biology. Second, what are the consequences of such essentialist perceptions? As outlined in the overview of current research above, Study 1 investigated whether essentialist perceptions of morality predicted participants' own generosity and expectations regarding others' generosity; subsequent studies manipulated essentialism to test causation. Third, how do patterns related to moral essentialism change or stay the same across development? To address this question, Study 1 compared 5- to 8-year-olds and adults.

\section{Method}

Participants. Based on recommendations to include approximately 50 participants per cell in psychological research (Lakens \& Evers, 2014; Simmons, Nelson, \& Simonsohn, 2013), Study 1 and each subsequent study sought to recruit approximately 50 participants in each age group, over-recruiting slightly with the expectation of excluding some participants. Sixty-two children between five and eight years old $\left(M_{\mathrm{age}}=6.61\right.$ years, $S D_{\mathrm{age}}=.96$ years, $61 \%$ female $)$ were recruited in a museum in a large city in the northeastern United States and received stickers. Our lab signed up for semester-long museum shifts, and we continued testing children until the end of the semester in order to avoid training research assistants on a new study that they would only be 
able to run during one or two shifts. Parents completed a demographic questionnaire during the session on which they identified their children as White or European American (29\%), Black or African American (36\%), Asian or Asian American (2\%), Multiracial (19\%), and "other" (2\%); the remaining parents did not answer this question. Parents indicated their child's ethnicity using a separate question, and $29 \%$ of participants were identified as Hispanic or Latina/o. Data from one additional child were excluded because she did not understand English.

Participants also included 57 adults between 21 and 73 years old $\left(M_{\mathrm{age}}=36.93\right.$ years, $S D_{\text {age }}=12.19$ years, $47 \%$ female). Adults completed a demographic questionnaire after answering all experimental items, and they self-identified as White or European American (79\%), Black or African American (5\%), Asian or Asian American (9\%), Native American or Pacific Islander (2\%), and Multiracial (4\%). Additionally, $7 \%$ of adults self-identified as Hispanic or Latina/o. Adults were recruited via Amazon Mechanical Turk and received \$1.32. They also completed a pilot task for an unrelated experiment; the order of the current study and the pilot task was counterbalanced across participants. Data from three additional adults were excluded because they did not correctly answer an attention check item asking them to recall any of the questions they had answered in the study $(n=1)$ or because they had previously completed a related study, which is described in the Supplemental Materials $(n=2)$. The patterns reported below for children and adults for all studies also emerged when analyzing data from all respondents.

Procedure. All procedures for this and each subsequent study were conducted in accordance with APA ethical standards. Procedures were approved by the IRB at the author's institution (protocol \#AAAQ8299, “The role of essentialism in children's and adults' moral cognition"). 
Children were greeted by an experimenter who told them that they would answer some questions that had no right or wrong answers. In Part I, the self-relevant essentialism questions, the experimenter asked children whether they thought they were a good person. Children were asked to reply by saying "yes" (coded as 3), "maybe" (coded as 2), or "no" (coded as 1), and all children responded either "yes" or "maybe." Using these same response options, children then completed a six-item essentialism scale from prior work (Gelman et al., 2007; Heiphetz, Gelman, \& Young, 2017). This scale included items such as, "Do you think that you were born a good person?" and, "Do you think that you have always been a good person?" The six items were averaged to create one composite score. See Appendix for all items and Supplemental Materials for additional analyses regarding this scale, including analyses showing similar patterns as those reported below when using non-parametric analyses.

In Part II, the sharing task, the experimenter showed children a closed envelope and said, "Look, here is an envelope that has some stickers in it. Someone else filled this envelope, so I don't know how many stickers are in there. I'm going to close my eyes, and I want you to take a look inside and decide how many of the stickers you want to keep." These instructions were designed to minimize self-presentation concerns; note also that subsequent studies asked participants to distribute resources between two other people rather than between themselves and one other person in part to determine whether the link between essentialism and generosity might emerge to a different extent when participants did not have the option to keep any resources for themselves.

The experimenter then showed children how to distribute the stickers between two additional envelopes, a blue envelope for stickers that children wanted to keep for themselves and a red envelope for stickers that children wanted to share with the next child who played this 
game (e.g., the next participant). After providing instructions, the experimenter asked children to remind him or her who would receive the stickers in the red envelope. Eighty-seven percent of children answered this question correctly on the first try. If children answered incorrectly, the experimenter reviewed the instructions and asked children again who would receive the stickers left in the red envelope. All children who answered incorrectly the first time provided a correct response to this second probe. To reduce self-presentation concerns, the experimenter indicated that he or she did not know how many stickers were initially in the envelope (e.g., ostensibly, the experimenter could not figure out what proportion of all available stickers the child decided to share), closed his or her eyes and turned away while participants distributed stickers, and did not look inside either the red or blue envelope while the child was present.

After children allocated the stickers, the experimenter put both envelopes aside until the end of the session and moved on to Part III of the experiment, the other-directed essentialism questions. (The sticker task interrupted the essentialism measure because participants were asked to indicate how many stickers others would share and thus needed to be familiar with the task; see below.) Part III included one block of essentialism questions regarding goodness and a separate block of essentialism questions regarding badness. ${ }^{1}$ In the goodness block, the experimenter said, “A person named Lucy/David [matched to participant gender] is a good person." The experimenter then asked each of the six essentialism questions from Part I, e.g.,

${ }^{1}$ Children also completed a block of essentialism measures regarding shyness. This characteristic was not directly relevant to the main questions of this research, but it has been tested in prior work using the same essentialism scale as the present work (Gelman et al., 2007) and could therefore provide information about whether children were using the scale as intended. In the earlier work, children showed some essentialism regarding shyness; if scores to the shyness questions were at floor in the current work, this may indicate that children in the current sample were confused about the scale or understood it differently than children in prior work. Responses were not at floor $(M=1.95, S D=.35)$ and were significantly higher than the lowest point of the scale $(t(60)=21.37, p<.001$, Cohen's $d=2.71)$, suggesting that children in the current sample understood how to use the scale. 
"Do you think that Lucy/David has always been a good person?" After these six questions, the experimenter asked, "If Lucy/David were playing the sticker game we just played, how many stickers do you think she/he would put in the red envelope for the next person?" The purpose of this question was to examine predictions regarding others' generosity. The badness block was identical except that the questions referred to a person named Karen or George and asked about his/her badness rather than goodness. The order of blocks, and the order of essentialism questions within each block, was counterbalanced across participants. After answering all items in Part III, participants received the stickers they had decided to keep for themselves as well as the stickers shared by the previous participant.

Adults completed the procedure described above via a self-paced computer task. Because stickers are unlikely to be an appealing resource to adults, they divided five entries into a lottery to win $\$ 10$.

\section{Results}

The analytic strategy proceeded in two stages. Stage 1 examined participants' responses to the essentialism measure in order to address the first main question targeted in this work, i.e., the extent to which people view moral goodness and moral badness in essentialist terms. Stage 2 investigated the relation between responses to the essentialism measure and generosity in order to address this project's second main question, i.e., the extent to which moral essentialism is associated with behavior (in this case, sharing resources with others). Stage 2 investigated participants' own generosity because perceptions of moral characteristics may be associated with how many resources participants want to share with others. For example, participants who see themselves as inherently good people may wish to act in line with that perception by sharing generously, and participants who see someone else's goodness as innate and immutable may 
share more resources with that person than participants who see someone else's goodness as dependent on external influences and potentially changeable over time. Stage 2 also investigated participants' expectations regarding others' generosity. As discussed in the introduction, adults view positive characteristics as especially good when they arise from an internal source (Tsay \& Banaji, 2011). Thus, for example, participants who view someone else's goodness as arising from an innate, internal source may expect that person to be particularly generous.

Both stages of analysis compared children and adults to address the third main question of this project, i.e., the extent to which children's responses may be similar to or different from adults' responses. Here and in all subsequent studies, multiple comparisons were adjusted by applying a Bonferroni correction to the alpha level. The text below reports uncorrected $p$ values along with the adjusted alpha. Additionally, the analyses below compare children and adults; see Supplemental Materials for more fine-grained analyses of participant age.

To What Extent Do Participants Show Moral Essentialism? A 2 (Participant Age: child vs. adult) x 3 (Category: self-goodness vs. other-goodness vs. other-badness) mixed ANOVA with repeated measures on the second factor investigated whether children and adults showed different levels of essentialism in each category. This analysis revealed a main effect of Participant Age $\left(F(1,113)=40.92, p<.001, \eta_{\mathrm{p}}{ }^{2}=.27\right)$. Consistent with prior work in non-moral domains (Chalik et al., 2017; Cimpian \& Steinberg, 2014; Diesendruck et al., 2013; Gelman et al., 2007; Heiphetz, Gelman, \& Young, 2017; Taylor et al., 2009), children reported more essentialism overall than did adults. The omnibus ANOVA also revealed a main effect of Category $\left(F(1.76,201.67)=35.82, p<.001, \eta_{\mathrm{p}}{ }^{2}=.24\right){ }^{2}$ To probe this effect, subsequent tests

\footnotetext{
${ }^{2}$ Here and in all subsequent ANOVAs, non-integer degrees of freedom reflect a Greenhouse Geisser correction for the violation of sphericity.
} 
compared each category with each other category; therefore, $p$ values needed to be .017 or lower to pass the Bonferroni-corrected significance threshold. Participants viewed others' badness in less essentialist terms than their own goodness $(p<.001$, Cohen's $d=-.66)$ or others' goodness $(p<.001$, Cohen's $d=-.62)$, which did not significantly differ from each other $(p=.078$, Cohen's $d=.18)$. The Participant Age x Category interaction did not reach significance ( $p=.187$; Figure 1$)$.

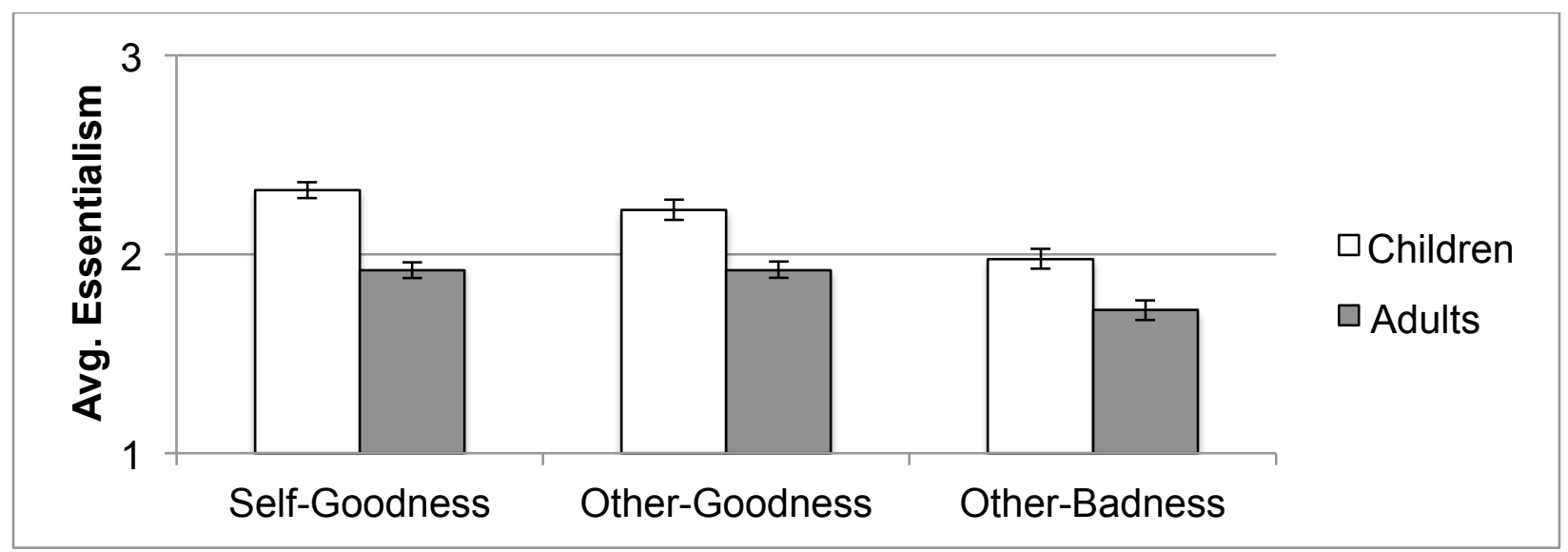

Figure 1. Average essentialism regarding one's own goodness, others' goodness, and others' badness, Study 1. Error bars represent the standard error of the mean.

What Is The Relation Between Essentialism And Generosity? Six correlations investigated whether essentialism in any of the three categories predicted children's or adults' generosity. $P$ values needed to be .008 or lower to pass the Bonferroni-corrected significance threshold, and none did so $(|r| \mathrm{s} \leq .30, p \mathrm{~s} \geq .018$; only one value fell below the traditional .05 threshold). Four additional correlations investigated whether essentialism in any category was associated with children's — and, separately, adults' — expectations regarding others' behaviors. In other words, these analyses examined whether the extent to which children and adults viewed goodness in essentialist terms predicted the extent to which they expected a good person to behave generously and whether the extent to which they viewed badness in essentialist terms predicted the extent to which they expected a bad person to behave generously. $P$ values needed 
to be .013 or lower to pass the Bonferroni-corrected significance threshold, and none did so $(|r| \mathrm{s} \leq .19, p \mathrm{~s} \geq .151)$

\section{Discussion}

The purpose of Study 1 was to address two questions. First, to what extent do children and adults view morality in an essentialist way? Patterns of responses among both children and adults suggested a greater tendency to view goodness, rather than badness, in essentialist terms. This finding is consistent with work indicating that adults view the "true self" as morally good (De Freitas et al., 2018; Newman et al., 2014) and suggests that characteristics that are seen as essentialist in one way (central to identity) may be seen as essentialist in other ways as well (e.g., as immutable and rooted in biology). The "good true self" effect has not previously been shown in children, but the consistent patterns among both children and adults in the current work suggest that children may also view people's true selves as morally good - a possibility that can be tested directly in future work. Further, the fact that both children and adults in the current work viewed goodness in more essentialist terms than badness suggests that this pattern is not dependent on adults' greater social experience and cognitive maturity.

Second, to what extent is essentialism associated with behavior? Study 1 did not find significant correlations between essentialist views of moral characteristics in general and participants' own generosity, nor did this study reveal significant correlations between essentialist views of morality and expectations regarding others' generosity. Study 2 investigated whether behavioral responses might show more sensitivity to information about the recipient of generosity rather than to views of abstract moral qualities.

\section{Study 2}


Study 2 had two main goals. First, it sought to replicate the results from Study 1. Second, it asked whether participants' generosity depends on essentialist representations of the specific recipient of their generosity rather than essentialism regarding moral characteristics broadly construed. Since participants shared resources with a specific other person, their views of that person may have influenced sharing more than did their views regarding morality in general.

\section{Method}

Participants. Participants included 57 children between five and eight years old $\left(M_{\mathrm{age}}=7.00\right.$ years, $S D_{\mathrm{age}}=.91$ years, $70 \%$ female $)$. Parents completed a demographic questionnaire during the session, on which they identified their children as White or European American (32\%), Black or African American (35\%), Asian or Asian American (9\%), Multiracial (14\%), and "other" $(5 \%)$; the remaining parents did not answer this question. Parents indicated their child's ethnicity using a separate question, and $14 \%$ of participants were identified as Hispanic or Latina/o. Participants also included 58 adults between 21 and 77 years old $\left(M_{\mathrm{age}}=33.61\right.$ years, $S D_{\text {age }}=11.09$ years, $33 \%$ female). Adults completed a demographic questionnaire after answering all experimental items, and they self-identified as White or European American (74\%), Black or African American (9\%), Asian or Asian American (10\%), Multiracial (5\%), and "other" (2\%). Additionally, 16\% of adults self-identified as Hispanic or Latina/o.

Recruitment and compensation were identical to Study 1 except that adults in Study 2 received $\$ 1$. No children were excluded from analyses. Two adults, not included in the demographic analyses above, were excluded for failing to correctly answer the same attention check item used in Study 1.

Procedure. Children answered the self-relevant and other-directed essentialism questions from Study 1 and then completed a modified version of the sharing task. Specifically, they 
viewed a Power Point display showing photographs of two children side-by-side. The children were White and of the same gender and approximate age as the participant. ${ }^{3}$ During the "bad character" trial for female participants, the experimenter pointed to the character on the left and described her in essentialist terms by saying, "This girl is a bad person. She is a bad person because she was born that way. Something in her brain makes her a bad person, and she couldn't change even if she wanted to." The experimenter then pointed to the character on the right and described her in non-essentialist terms by saying, "And here is another girl who is a bad person. She is a bad person because she learned to be that way from other people. The way that her friends and family act towards her makes her a bad person, and she could change if she wanted to." During the "good character" trial, participants viewed two different people (not the same ones shown during the "bad character" trial). One character was described using the essentialist description above, except the word "bad" was replaced with the word "good," while the other character was described using the non-essentialist description. ${ }^{4}$ Following the descriptions, the experimenter asked participants to remind him or her why each character was bad (or good) and corrected the few participants who answered incorrectly (ranging from two to seven participants across descriptions).

After children had answered the memory check item regarding the bad character, the experimenter gave them a closed envelope and said, "In this envelope are some stickers. Now, I

\footnotetext{
${ }^{3}$ Because all photographs depicted White characters, three independent-samples $t$-tests investigated whether non-Hispanic White participants shared a different number of resources with good, bad, and shy characters (see Footnote 1) described in essentialist terms than did nonWhite and White Hispanic participants. These analyses did not reveal significant differences $(|t \mathrm{~s}| \leq .60, p \mathrm{~s} \geq .553$, Cohen's $d \mathrm{~s} \leq .17)$.

${ }^{4}$ Characters in a third pair were described as shy for either essentialist or non-essentialist reasons. The number of resources participants shared with the shy character described in essentialist terms did not differ from chance (children: $M=2.65, S D=.91, t(53)=1.19, p=.239$, Cohen's $d=.16$; adults: $M=2.42, S D=1.09, t(57)=.54, p=.590$, Cohen's $d=-.07)$.
} 
don't know how many stickers are inside of this envelope because someone else filled the envelope." The experimenter then showed children how to distribute the stickers between two additional envelopes, one placed in front of the photograph of the character described in essentialist terms and the other placed in front of the photograph of the character described in non-essentialist terms, and reminded children that they had to distribute all stickers between the two characters. As in Study 1, the experimenter sought to reduce self-presentation concerns by closing his or her eyes and turning around while participants distributed stickers. This same procedure was followed after children had learned about the two good characters; that is, children distributed stickers between each pair of characters immediately after hearing the relevant descriptions and then moved on to the next pair.

Across participants, each characteristic was paired with different photographs. The following were counterbalanced across participants: (1) the order in which participants distributed stickers to good versus bad characters; (2) the side of the screen on which each character appeared; (3) the photograph paired with each description (e.g., one photograph was described as bad for essentialist reasons for some participants, bad for non-essentialist reasons for other participants, good for essentialist reasons for other participants, and good for nonessentialist reasons for other participants).

Adults completed a similar procedure, with several exceptions. First, they participated via a self-paced computer task. Second, they read descriptions of characters without viewing photographs; images were used to draw children's attention to the stimuli, which was not necessary with adults. Because the description was in front of adults during the sharing task (e.g., they indicated how many entries they wanted to allocate to someone who was born bad, etc.), adults did not answer memory check questions testing which character was described in which 
way. Third, rather than distributing five stickers, adults distributed five entries into a lottery for $\$ 10$. As in Study 1 , this change was made because stickers are valuable to children but likely far less valuable to adults, who may place more value on money. Fourth, the adult version of the study included Bastian and Haslam's (2006) essentialism scale, which was developed for adults and therefore not provided to the child participants. This measure predicted essentialism regarding participants' own goodness, others' goodness, and others' badness $(r s \geq .58, p s<.001)$ and did not significantly predict the number of resources participants shared with any character $(|r| \mathrm{s} \leq .22, p \mathrm{~s} \geq .100)$. Due to the exploratory nature of this measure, it will not be discussed further. These types of minor modifications (in-person versus online testing; using images with children only) are common when testing both children and adults (Cogsdill, Todorov, Spelke, \& Banaji, 2014; Heiphetz, Strohminger, Gelman, \& Young, 2018; Roussos \& Dunham, 2016; Smith \& Warneken, 2016; Starmans \& Bloom, 2016) and have not influenced participants' responses in prior work (Heiphetz, Spelke, Harris, \& Banaji, 2013; Heiphetz et al., 2018).

\section{Results}

To What Extent Do Participants Show Moral Essentialism? One child and six adults reported that they were not good people; their scores on questions regarding their own goodness were removed, although these participants contributed data to essentialism regarding others' characteristics.

The first goal of Study 2 was to determine whether the essentialism measure replicated Study 1's results. To investigate this question, a 2 (Participant Age: child vs. adult) x 3 (Category: self-goodness vs. other-goodness vs. other-badness) mixed ANOVA with repeated measures on the second factor examined essentialism. As in Study 1, this analysis revealed a main effect of Participant Age $\left(F(1,104)=49.64, p<.001, \eta_{\mathrm{p}}{ }^{2}=.16\right)$; children reported more 
essentialism overall than did adults. Also as in Study 1, the omnibus ANOVA further revealed a main effect of Category $\left(F(1.78,185.23)=39.93, p<.001, \eta_{\mathrm{p}}{ }^{2}=.28\right)$. To probe this effect, I compared each category with each other category; therefore, $p$ values needed to be .017 or lower to pass the Bonferroni-corrected significance threshold. As in Study 1, participants viewed others' badness in less essentialist terms than their own goodness $(p<.001$, Cohen's $d=-.74)$ or others' goodness $(p<.001$, Cohen's $d=-.60)$; unlike Study 1, participants also viewed their own goodness in more essentialist terms than others' goodness ( $p=.006$, Cohen's $d=.25)$. The Participant Age x Category interaction did not reach significance ( $p=.115$; Figure 2).

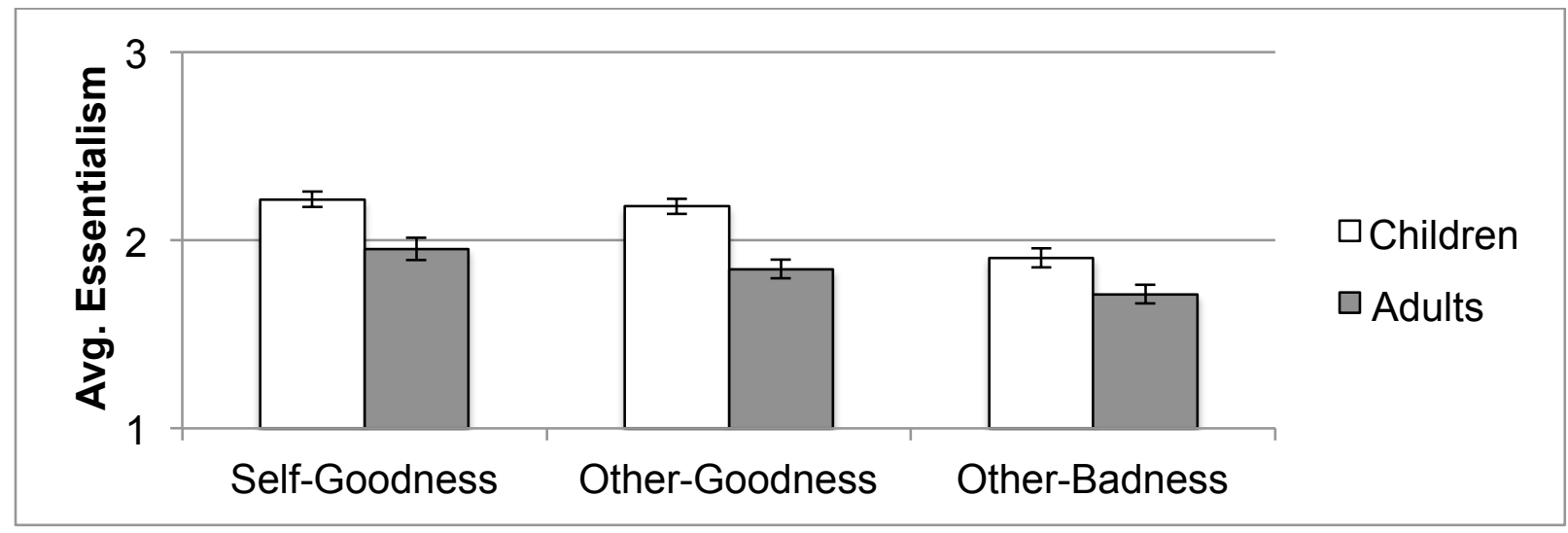

Figure 2. Average essentialism regarding one's own goodness, others' goodness, and others' badness, Study 2. Error bars represent the standard error of the mean.

What Is The Relation Between Essentialism And Generosity? The second goal of Study 2 was to determine the extent to which essentialist versus non-essentialist character descriptions influenced participants' sharing. To achieve this goal, the number of resources participants shared with the character described in essentialist terms in each pair served as the dependent measure in each analysis. Recall that each pair consisted of two characters who shared the same characteristic; however, that characteristic was described in essentialist terms for one character and non-essentialist terms for the other character. Participants then split resources 
between these characters, such that the number shared with the character described in essentialist terms is inversely related to the number shared with the character described in non-essentialist terms.

To determine whether participants' sharing with these characters differed from chance, a one-sample $t$-test compared the number of resources that children and, separately, adults shared with each character described in essentialist ways to 2.5 (the number of resources that participants would be expected to share with that character, on average, if they were dividing the resources equally between the two characters). This analysis included four comparisons; therefore, $p$ values needed to be .013 or lower to pass the Bonferroni-corrected significance threshold. Adults shared fewer resources with the bad character described in essentialist terms than would be expected by chance $(t(56)=-4.54, p<.001$, Cohen's $d=-.60)$. No other analyses reached significance ( $p \mathrm{~s} \geq .219, \mid$ Cohen's $d \mid \mathbf{s} \leq .17)$. For ease of interpretation, Figure 3 illustrates the raw number of resources shared with each character.

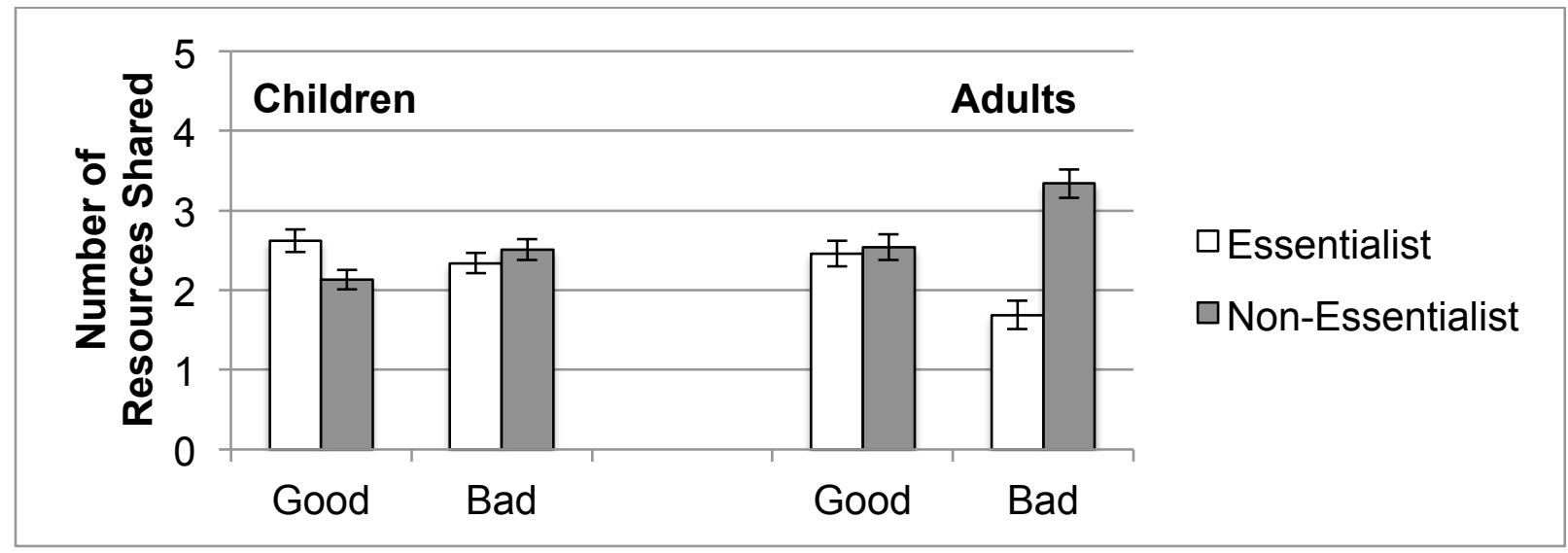

Figure 3. Number of resources shared with good and bad characters described in essentialist versus non-essentialist ways, Study 2. Error bars represent the standard error of the mean.

\section{Discussion}


The goals of Study 2 were twofold. First, this study sought to determine whether the patterns observed regarding essentialist views of morally relevant characteristics in Study 1 would replicate in a new sample. Indeed, Study 2, like Study 1, showed that children reported more essentialism than did adults and that participants in both age groups viewed good characteristics in particularly essentialist terms. Second, Study 2 tested whether individuals' generosity might depend on the extent to which the recipients of that generosity were described in essentialist terms. The main result showed that adults shared fewer resources with the bad character described in essentialist terms (and therefore more resources with the bad character described in non-essentialist terms) than would have been expected by chance. Study 3 sought to determine whether this effect would replicate in a new sample of adults and whether it might depend on (a) socially desirable responding and/or (b) the particular phrasing used to describe moral characteristics in essentialist versus non-essentialist terms.

\section{Study 3}

A final, pre-registered study (https://academiccommons.columbia.edu/doi/10.7916/d8vr03-cp64) investigated several alternative explanations for the results from Studies 1-2. First, in these earlier studies, participants answered questions about the extent to which they perceived their own goodness in essentialist terms and only then answered questions about others' characteristics. Answering questions about themselves first may have led participants to rate other people's goodness as similar to their own. This concern is somewhat attenuated by an additional study presented in Supplemental Materials that did not include questions about essentialism regarding the self but nevertheless found similar relations between others' goodness and badness as the studies reported in the main text. However, to investigate this possibility more fully, participants in Study 3 answered questions about their own goodness after questions about 
others' characteristics. As in earlier studies, the order in which participants answered questions about others' goodness and badness was counterbalanced.

Second, in Study 2, the essentialist description noted that the characteristic was unchanging, whereas the non-essentialist explanation noted that the character could change. This component was included because essentialized characteristics are typically perceived to be immutable (e.g., Gelman, 2003). This feature is so central to essentialism that it is commonly included on essentialism measures, with high agreement that characteristics are immutable serving as evidence of essentialism (Bastian \& Haslam, 2006; Gelman et al., 2007; Heiphetz, Gelman, \& Young, 2017). However, in the current design, giving a relatively small number of resources to a bad character who would stay bad forever could reflect judgments about recidivism rather than judgments about essentialism per se. Thus, in Study 3 , the essentialist and non-essentialist descriptions both stated that the person would stay the same forever while varying the reason for that stability.

Third, because adults learned about all characters in the resource-sharing part of Study 2, they may have shared fewer resources with the bad character described in essentialist (versus non-essentialist) terms due to demand characteristics. To address this possibility, participants in Study 3 completed a measure of social desirability and indicated what they believed the hypothesis of the study to be.

\section{Method}

Participants. Because the effect of essentialist descriptions on generosity emerged only among adults in Study 2, Study 3 only included an adult sample (56 participants between 20 and 61 years old, $M_{\text {age }}=33.04$ years, $S D_{\text {age }}=9.41$ years, $50 \%$ female . On a demographic questionnaire completed at the end of the study, participants self-identified as White or European American 
(73\%), Black or African American (14\%), Asian or Asian American (4\%), Native American or Pacific Islander (4\%), and “other" (4\%). Additionally, 16\% of adults self-identified as Hispanic or Latina/o. Participants were recruited via Amazon Mechanical Turk and received \$1. They completed the same attention check item used in Studies 1-2. Fifteen adults, not included in these demographic analyses, were excluded from analyses because they did not answer this question correctly.

Procedure. The procedure was identical to that followed by adults in Study 2, with the following exceptions. First, as described above, participants answered questions about their own goodness after answering questions about others' characteristics. Second, the sharing task described characteristics as unchanging in each condition while varying the reason for the immutability. The essentialist description of the bad character described her (or him, for male participants) as a 'bad person because she was born that way. Something in this person's brain makes her a bad person. Her badness is an inborn, central part of her personality, so she will always be bad. Even when she is very old, this person will still have the same essential personality and will continue being bad." The non-essentialist description of the bad character described her as a "bad person because she learned to be that way. The way that other people treat her makes her a bad person. These people will treat her the same way forever, so she will always be bad. Even when she is very old, this person will remember what she learned from others and continue being bad." The good characters were described in this same way, except that the word "bad" was replaced with "good." Third, after answering all experimental items, participants completed a social desirability scale (Crowne \& Marlowe, 1960). This measure is

\footnotetext{
${ }^{5}$ As in Study 2, participants also distributed resources between a shy character described in essentialist versus non-essentialist terms. The number of resources shared with the shy character described in non-essentialist terms did not differ from chance $(M=2.34, S D=.82, t(55)=-1.48$, $p=.146$, Cohen's $d=-.18$ ).
} 
composed of 33 items that participants mark as "true" (coded as 1) or "false" (coded as 0).

Sample items include, "I never hesitate to go out of my way to help someone in trouble" and, "I always try to practice what I preach." Fourth, after completing the social desirability scale and a demographic questionnaire, participants indicated what they thought the study was trying to test. ${ }^{6}$

\section{Results}

To What Extent Do Participants Show Moral Essentialism? Study 3 first sought to determine whether the essentialism measure replicated the patterns observed in Studies 1-2 if participants answered questions about themselves after, rather than before, answering questions about other people. A one-factor, three-level (Category: other-goodness vs. other-badness vs. self-goodness) repeated measures ANOVA examined this possibility and revealed a main effect of Category $\left(F(1.74,95.57)=7.74, p=.001, \eta_{\mathrm{p}}{ }^{2}=.12\right)$. To further probe this effect, follow-up analyses compared each category with each other category, for a total of three comparisons; therefore, $p$ values needed to be .017 or lower to pass the Bonferroni-corrected significance threshold. As in Studies 1-2, participants reported less essentialism regarding others' badness

\footnotetext{
${ }^{6}$ Study 3 also investigated whether perceived similarity might mediate the relation between type of description (essentialist versus non-essentialist) and sharing. Prior work has argued that people may perceive themselves to be less similar to others who are described in essentialist versus non-essentialist terms (e.g., Williams \& Eberhardt, 2008). Further, individuals show greater generosity towards people they perceive as more similar to themselves (e.g., Johnson \& Smirnov, 2018; Kogut \& Ritov, 2007). Thus, it may be the case that the essentialist description of the bad character predicted lower perceived similarity to that character, which, in turn, predicted less sharing with that character. To test this possibility, participants indicated how similar they perceived each character to be to themselves on a scale from 1 ("not at all similarthis person is very different from me") to 5 ("very similar"). Participants rated their perceived similarity to all characters, in randomized order, immediately before completing the sharing task. Participants did perceive the bad character described in essentialist terms as less similar to themselves than the bad character described in non-essentialist terms $\left(M_{\text {essentialist }}=2.04\right.$, $S D_{\text {essentialist }}=1.14, M_{\text {non-essentialist }}=2.46, S D_{\text {non-essentialist }}=1.31, t(55)=-2.23, p=.030$, Cohen's $\left.d=-.30\right)$, and the extent to which they perceived the bad character described in essentialist terms as similar to them predicted the number of resources they shared with that character $(r=.301, p=.024)$. However, a mediation analysis using 5,000 bootstrapped samples (Montoya \& Hayes, 2017) did not reveal a significant indirect effect $(b=-.08,95 \%$ CI: $[-.35, .08])$.
} 
than regarding others' goodness ( $p=.004$, Cohen's $d=-.40$ ) or their own goodness ( $p=.002$,

Cohen's $d=-.43$ ). Responses regarding others' goodness and participants' own goodness did not differ from each other ( $p=.459$, Cohen's $d=.10$; Figure 4$){ }^{7}$

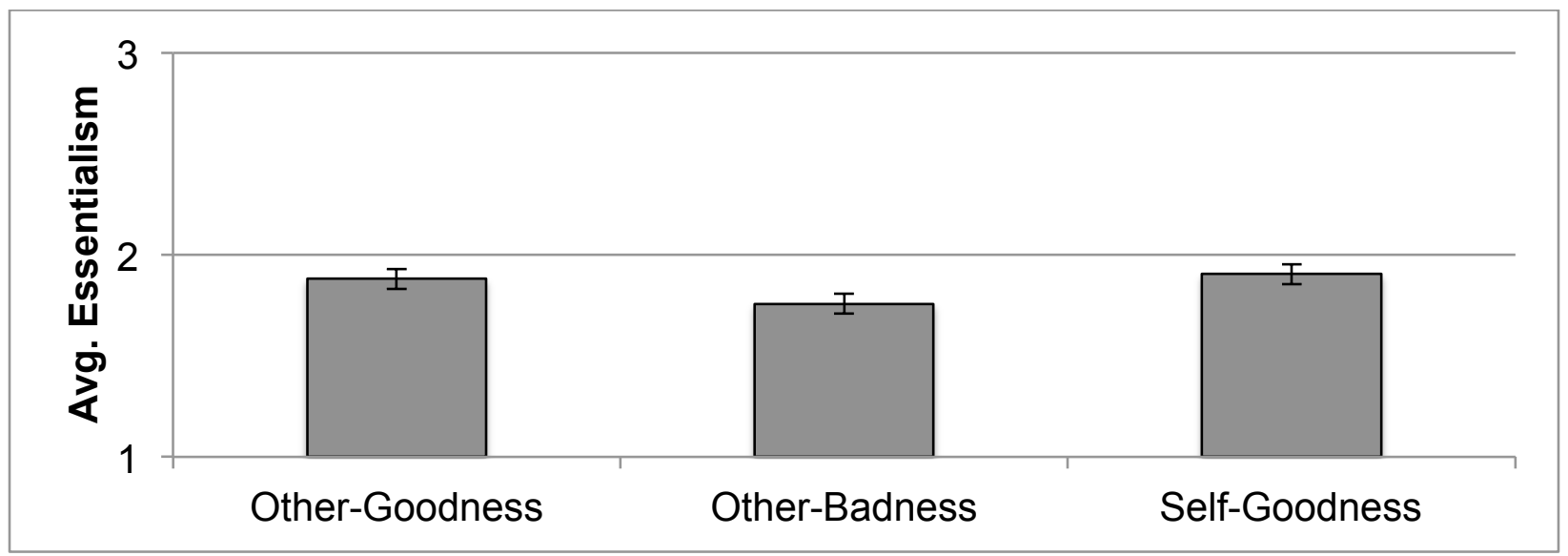

Figure 4. Adults' average essentialism regarding others' goodness, others' badness, and their own goodness, Study 3. Error bars represent the standard error of the mean.

What Is The Relation Between Essentialism And Generosity? Subsequent analyses sought to determine whether Study 3 demonstrated the same pattern of generosity as did Study 2 . As in Study 2, one-sample $t$-tests compared the number of resources adults shared with the good and bad characters who were described in essentialist terms to 2.5. Because this included two comparisons, $p$ values needed to be .025 or lower to pass the Bonferroni-corrected significance threshold. As in Study 2, adults shared fewer resources with the bad character described in essentialist terms than would be expected by chance $(t(55)=-4.60, p<.001$, Cohen's $d=-.62)$, but

\footnotetext{
${ }^{7}$ The analysis specified in the pre-registration included shyness in the main ANOVA. This analysis revealed similar results to those described above. That is, a one-factor, four-level (Category: other-goodness vs. other-badness vs. self-goodness vs. shyness) repeated-measures ANOVA revealed a main effect of Category, $F(2.26,124.21)=6.92, p=.001, \eta_{\mathrm{p}}{ }^{2}=.11$. Six pairwise comparisons then compared each category with each other category; therefore, $p$ values needed to be .008 or lower to remain significant after a Bonferroni correction. Participants viewed badness in less essentialist terms than any other characteristic ( $p \mathrm{~s} \leq .004$, Cohen's $d \mathrm{~s} \geq .40$ ). No other pairwise comparisons reached significance ( $p \mathrm{~s} \geq .060$, Cohen's $d s \leq .26$ ).
} 
their sharing with the good character described in essentialist terms did not differ from chance $(t(55)=.29, p=.776$, Cohen's $d=.04) .{ }^{8}$ For ease of interpretation, Figure 5 illustrates the raw number of resources shared with each character.

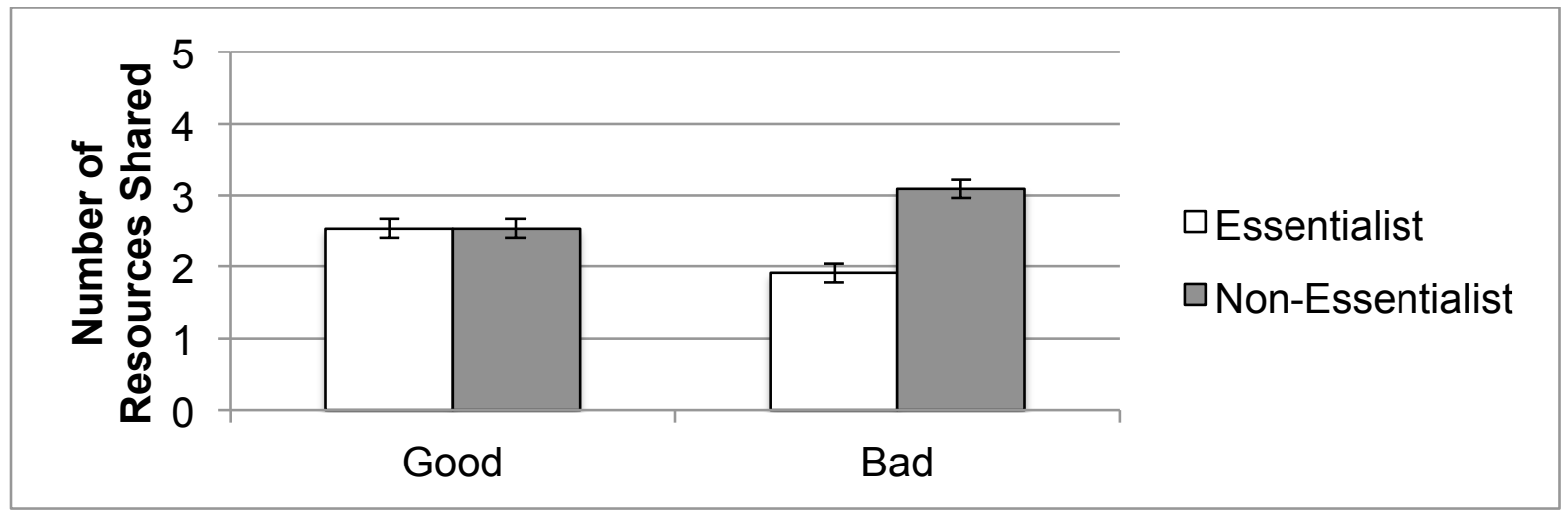

Figure 5. Number of resources adults shared with good and bad characters described in essentialist versus non-essentialist ways, Study 3. Error bars represent the standard error of the mean.

What Role Do Demand Characteristics Play In Participants' Responses? Two sets of analyses investigated whether demand characteristics may have played a role in adults' sharing behaviors. First, two correlations investigated whether scores on the social desirability scale predicted the number of resources adults shared with the good and bad characters described in essentialist terms. Thus, $p$ values needed to be .025 or lower to pass the Bonferroni-corrected significance threshold, and neither did so $(|r| \mathrm{s} \leq .03, p \mathrm{~s} \geq .829)$. Second, I coded participants' guesses about the study's hypothesis. The purpose of this item was to determine whether participants who correctly guessed the hypothesis responded differently from participants who

\footnotetext{
${ }^{8}$ Sharing with the shy character described in essentialist terms also did not differ from chance $(M=2.34, S D=.82, t(55)=-1.48, p=.146$, Cohen's $d=-.20)$. Because participants were required to split five resources between the character described in essentialist terms and the character described in non-essentialist terms, comparing the number of resources shared with the former character to chance is mathematically equivalent to comparing the number of resources shared with the latter character to chance.
} 
did not. However, no participants guessed the hypothesis. Many participants stated that they did not know, and when participants did articulate a possible hypothesis, they did not state any prediction about differential giving based on essentialist or non-essentialist descriptions (sample guesses included "I believe this was a test about nature vs nurture and what people believe in regard to it" and "whether we think certain behavior is learned or innate").

\section{Discussion}

Study 3 tested three alternative explanations for the results from Studies 1-2. First, in these earlier studies, participants' responses about their own goodness may have influenced their perceptions of others' characteristics. To address this possibility, participants in Study 3 answered questions about themselves after the questions about others. As in earlier studies, participants reported more essentialism about goodness than about badness. (See also Supplemental Materials, which present analyses showing that others' goodness elicits more essentialism than others' badness even when participants are not ever asked about their own goodness.)

Second, Study 3 probed whether adults would give more to a bad person described in non-essentialist, versus essentialist, ways when both people were described as unchangingly bad. Indeed, participants did give more to the bad character described in non-essentialist terms even when badness was described as unchanging for both characters.

Third, Study 3 investigated whether adults' sharing might be driven by demand characteristics. Results did not show a significant relation between giving to the characters described in essentialist terms and responses to a measure of social desirability (Crowne \& Marlowe, 1960). Further, no participant in Study 3 correctly guessed the hypothesis regarding greater giving to bad characters described in non-essentialist, versus essentialist, terms. 


\section{General Discussion}

The current work was designed to answer three questions. First, to what extent do people view moral characteristics in essentialist terms? Prior work suggests that adults view moral goodness as central to others' identities (De Freitas et al., 2018; Heiphetz, Strohminger, Gelman, \& Young, 2018; Newman et al., 2014; Strohminger \& Nichols, 2014), and perceived identity centrality is one component of essentialism (Haslam et al., 2000; Heiphetz, Strohminger, \& Young, 2017). Thus, adults may also perceive goodness in more essentialist terms than badness when answering questions about other components of essentialism, such as the perception that a characteristic is rooted in biology and remains stable over time. The current work supports this possibility by showing that adults (as well as children, see below) view goodness in more essentialist terms — that is, more biological and immutable — than badness. This finding contributes to theories of essentialism by indicating that characteristics that elicit one component of essentialism, such as perceptions of identity centrality, may elicit additional components as well.

Second, what are the consequences of viewing moral characteristics in an essentialist way? Neither Study 1 nor a replication study using the same measures (see Supplemental Materials) found a significant relation between essentialist views of moral characteristics in general and generosity toward another person. However, Studies 2-3 revealed that essentialism regarding the characteristics of the specific recipient of generosity can guide behavior. The strongest effect emerged among adults distributing resources to two characters described as bad people. In both Studies 2 and 3, adults shared fewer resources than would be expected by chance with the bad person who was described in essentialist terms (e.g., as being bad from birth due to biological factors); since adults shared resources from a limited pool, this also indicates that they 
gave more resources to the bad character described in non-essentialist terms. This finding extends prior work highlighting the negative consequences of viewing entire domains in essentialist terms. For example, in one line of work, adults expressed greater acceptance of racial inequality and a lesser desire to interact with out-group members when they were led to view race as biological rather than socially constructed (Williams \& Eberhardt, 2008). However, this past work has not focused on testing whether essentialist views of different sub-categories (e.g., Blackness versus Whiteness or, here, goodness versus badness) might be differentially associated with pro-sociality (but see Haslam et al., 2000, for an exception). Although some work with children has investigated essentialist views of goodness versus badness (Heyman \& Dweck, 1998; Heyman \& Gelman, 2000), this work did not investigate what consequences essentialism might have for generosity. The current finding thus contributes to work on essentialism and prosocial behavior by highlighting the consequences that essentialist views of badness, in particular, may hold for adults' behaviors.

Third, how do patterns related to moral essentialism stay or change the same across development? Past work leads to two competing predictions regarding potential similarities or differences among age groups regarding moral essentialism. On the one hand, children report optimistic evaluations of others (e.g., Aloise, 1993; Tasimi et al., 2017). Thus, like adults, they may perceive goodness as a central component of identity and may judge goodness in particularly essentialist terms when answering questions about biology and stability as well. On the other hand, children typically report relatively high levels of essentialism, higher than those demonstrated by adults (Cimpian \& Steinberg, 2014; Gelman et al., 2007; Heiphetz, Gelman, \& Young, 2017). Children's propensity to view human characteristics in essentialist terms may be so strong that it overwhelms any difference between sub-categories of the same characteristic, 
leading them to report relatively high levels of essentialism regarding both goodness and badness. The current work supported the first possibility, showing that children-like adultsviewed goodness in more essentialist terms than badness.

In addition to investigating moral essentialism across development, the present research also probed whether the consequences of this type of essentialism may differ across age groups. As discussed in the previous paragraph, children typically report high levels of essentialism. Thus, providing them with an essentialist explanation for another person's moral characteristic may align with their own understanding of that characteristic and therefore not strongly change their behavior. In contrast, adults typically report far less essentialism than children (Cimpian \& Steinberg, 2014; Gelman et al., 2007; Heiphetz, Gelman, \& Young, 2017). Therefore, when an essentialist explanation is provided, it may influence adults' behaviors to a larger extent. The results from Studies 2-3 support these possibilities. In these studies, telling adults that someone's badness arose from internal factors reduced their sharing, causing them to give fewer resources than would be expected by chance to the bad character described in essentialist terms (and therefore more resources to the bad character described in non-essentialist terms). In contrast, children shared the same number of resources, on average, with characters described in essentialist versus non-essentialist ways. In other words, adults' behaviors were more sensitive than children's behaviors to information about the extent to which badness arises from an internal source - a finding consistent with work showing that information about internal qualities influences the judgments of older participants more than those of younger participants (Cushman et al., 2013; Helwig et al., 2001; Zelazo et al., 1996).

The current findings raise several important points for future research. For example, the current research used a paired generosity task in which participants received a set number of 
resources and were required to distribute all resources between two people who shared the same moral characteristic and differed only in how that moral characteristic was described. This approach makes it possible to test generosity toward people described as bad; if participants viewed characters one at a time, they may have refused to share any resources with "bad" people. However, this strategy makes it impossible to determine which character was driving the effect. Future research could include a third character whose badness is not explained in order to determine whether essentialist explanations decrease generosity or non-essentialist explanations increase generosity relative to a control, or whether both effects happen simultaneously.

Future work can also probe why participants respond as they do. The current research posited that similarity may function as a mediator (in other words, perhaps participants perceive the non-essentialist character as less similar to themselves and give fewer resources to people perceived as less similar). However, the data did not support this possibility (see Footnote 6). There are many other mechanisms that could explain adults' (lack of) generosity, including pity for the character described in non-essentialist terms or the perceptions that that character is a victim of circumstance, and future work can test these alternatives.

In addition to the contributions outlined above to the study of essentialism, moral cognition, and social cognitive development, the present research also offers translational implications and directions for future research. During everyday life, individuals who have committed moral transgressions may seek forgiveness or generosity from others. In these situations, it may be beneficial to speak of one's transgression in non-essentialist ways rather than attributing the transgression to one's unchanging biological essence, a possibility that can be tested in future work. 
The importance of non-essentialist language may generalize beyond routine, everyday transgressions to transgressions that are perceived as more severe, such as those leading to incarceration. While much work in the social sciences highlights societal inequalities that lead to mass incarceration (Alexander, 2012; Forman, 2017; Travis, Western, \& Redburn, 2014), some scholarship also depicts criminality as arising from internal, biological factors (Eysanck, 1964; Mededovic, 2017; Raine, 2013). The current work suggests that the former framing can result in audience members' greater willingness to behave pro-socially toward people who have been involved in the justice system than the latter framing. In general, the current national conversation around criminal justice reform may benefit from knowing that highlighting social factors leading to incarceration and a person's ability to change can lead to greater generosity, while highlighting an incarcerated person's inherent, unchanging badness can reduce generosity. Of course, the present work did not test cognition or behavior in the context of criminal justice, and future work is needed to clarify essentialism's consequences in this domain. For example, future studies could examine the consequences of essentialist and non-essentialist language on recidivism, support for criminal justice reform, and other variables relevant to the justice system. However, the current work does begin to suggest that using non-essentialist language may benefit people who have transgressed — which, at some point, will be all of us.

\section{Conclusions}

By portraying the possibility that badness is innate, unchanging, and rooted in biology, the film The Bad Seed presented viewers with an essentialist explanation for immorality. Although the current work suggests that children and adults are more likely to perceive goodness — rather than badness — in essentialist terms, it also highlights the consequences of essentialism regarding badness. Specifically, adults shared less with a character whose badness 
was described in essentialist terms than would be expected by chance (and thus also shared more with a character whose badness was described in non-essentialist terms). Views such as those held by Rhoda's mother may be particularly consequential, and presenting non-essentialist explanations that counteract such views can increase pro-social behavior. 


\section{References}

Alexander, M. (2012). The new Jim Crow: Mass incarceration in the age of colorblindness.

New York, NY: The New Press.

Aloise, P. A. (1993). Trait confirmation and disconfirmation-The development of attribution biases. Journal of Experimental Child Psychology, 55, 177-193. doi:

10.1006/jecp.1993.1010

Alvarez, J. M., Ruble, D. N., \& Bolger, N. (2001). Trait understanding or evaluative reasoning? An analysis of children's behavioral predictions. Child Development, 72, 1409-1425. doi: $10.1111 / 1467-8624.00356$

Bastian, B., \& Haslam, N. (2006). Psychological essentialism and stereotype endorsement. Journal of Experimental Social Psychology, 42, 228-235. doi: 10.1016/j.jesp.2005.03.003

Boseovski, J. J., \& Lee, K. (2006). Children's use of frequency information for trait categorization and behavioral prediction. Developmental Psychology, 42, 500-513. doi: $10.1037 / 0012-1649.42 .3 .500$

Brescoll, V., \& LaFrance, M. (2004). The correlates and consequences of newspaper reports of research on sex differences. Psychological Science, 15, 515-520. doi: 10.1111/j.09567976.2004.00712.x

Chalik, L., Leslie, S. J., \& Rhodes, M. (2017). Cultural context shapes essentialist beliefs about religion. Developmental Psychology, 53, 1178-1187. doi: 10.1037/dev0000301

Cimpian, A., \& Steinberg, O. D. (2014). The inherence heuristic across development: Systematic differences between children's and adults' explanations for everyday facts. Cognitive Psychology, 75, 130-154. doi: 10.1016/j.cogpsych.2014.09.001

Cogsdill, E. J., Todorov, A. T., Spelke, E. S., \& Banaji, M. R. (2014). Inferring character from 
faces: A developmental study. Psychological Science, 25, 1132-1139. doi:

$10.1177 / 0956797614523297$

Crowne, D. P., \& Marlowe, D. (1960). A new scale of social desirability independent of psychopathology. Journal of Consulting Psychology, 24, 349-354. doi: $10.1037 / \mathrm{h} 0047358$

Cushman, F., Sheketoff, R., Wharton, S., \& Carey, S. (2013). The development of intent-based moral judgment. Cognition, 127, 6-21. doi: 10.1016/j.cognition.2012.11.008

Dar-Nimrod, I., \& Heine, S. J. (2011). Genetic essentialism: On the deceptive determinism of DNA. Psychological Bulletin, 137, 800-818. doi: 10.1037/a0021860

De Freitas, J., Sarkissian, H., Newman, G. E., Grossman, I., De Brigard, F., Luco, A., \& Knobe, J. (2018). Consistent belief in a good true self in misanthropes and three interdependent cultures. Cognitive Science, 42, 134-160. doi: 10.1111/cogs.12505

Diesendruck, G., Birnbaum, D., Deeb, I., \& Segall, G. (2013). Learning what is essential: Relative and absolute changes in children's beliefs about the heritability of ethnicity. Journal of Cognition and Development, 14, 546-560. doi:

$10.1080 / 15248372.2012 .691142$

Eysenck, H. J. (1964). Crime and personality. New York, NY: Routledge.

Forman, J., Jr. (2017). Locking up our own: Crime and punishment in Black America. New York, NY: Farrar, Straus and Giroux.

Gaither, S. E., Schultz, J. R., Pauker, K., Sommers, S. R., Maddox, K. B., \& Ambady, N. (2014). Essentialist thinking predicts decrements in children's memory for racially ambiguous faces. Developmental Psychology, 50, 482-488. doi: 10.1037/a0033493

Gelman, S. A. (2003). The essential child: Origins of essentialism in everyday thought Oxford 
University Press, New York, NY.

Gelman, S. A., Heyman, G. D., \& Legare, C. H. (2007). Developmental changes in the coherence of essentialist beliefs about psychological characteristics. Child Development, 78, 757-774. doi: 10.1111/j.1467-8624.2007.01031.x

Gravetter, F. J., \& Wallnau, L. B. (2007). Statistics for the behavioral sciences. Belmont, CA: Thomson Wadsworth.

Haslam, N., \& Levy, S. R. (2006). Essentialist beliefs about homosexuality: Structure and implications for prejudice. Personality and Social Psychology Bulletin, 32, 471-485. doi: $10.1177 / 0146167205276516$

Haslam, N., Rothschild, L., \& Ernst, D. (2000). Essentialist beliefs about social categories. British Journal of Social Psychology, 39, 113-127. doi: 10.1348/014466600164363

Heiphetz, L., Gelman, S. A., \& Young, L. L. (2017). The perceived stability and biological basis of religious beliefs, factual beliefs, and opinions. Journal of Experimental Child Psychology, 156, 82-98. doi: 10.1016/j.jecp.2016.11.015

Heiphetz, L., Spelke, E. S., Harris, P. L., \& Banaji, M. R. (2013). The development of reasoning about beliefs: Fact, preference, and ideology. Journal of Experimental Social Psychology, 49, 559-565. doi: 10.1016/j.jesp.2012.09.005

Heiphetz, L., Strohminger, N., Gelman, S. A., \& Young, L. L. (2018). Who am I? The role of moral beliefs in children's and adults' understanding of identity. Journal of Experimental Social Psychology, 78, 210-219. doi: 10.1016/j.jesp.2018.03.007

Heiphetz, L., Strohminger, N., \& Young, L. L. (2017). The role of moral beliefs, memories, and preferences in representation of identity. Cognitive Science, 41, 744-767. doi: $10.1111 / \operatorname{cogs} .12354$ 
Helwig, C. C., Zelazo, P.D., \& Wilson, M. (2001). Children's judgments of psychological harm in normal and noncanonical situations. Child Development, 72, 66-81. doi: $10.1111 / 1467-8624.00266$

Heyman, G. D., \& Dweck, C. S. (1998). Children's thinking about traits: Implications for judgments of the self and others. Child Development, 69, 391-403. doi: 10.1111/j.14678624.1998.tb06197.x

Heyman, G. D., \& Gelman, S. A. (2000). Beliefs about the origins of human psychological traits. Developmental Psychology, 36, 663-678. doi: 10.1037//0012-1649.36.5.663

Jayaratne, T. E., Ybarra, O., Sheldon, J. P., Brown, T. N., Feldbaum, M., Pfeffer, C., \& Petty, E. M. (2006). White Americans' genetic lay theories of race difference and sexual orientation: Their relationship with prejudice toward Blacks, and gay men and lesbians. Group Processes \& Intergroup Relations, 9, 77-94. doi:10.1177/1368430206059863

Johnson, T., \& Smirnov, O. (2018). Inequality as information: Wealth homophily facilitates the evolution of cooperation. Scientific Reports, 8, 11605. doi: 10.1038/s41598-018-30052-1

Kogut, T., \& Ritov, I. (2007). "One of us": Outstanding willingness to help save a single identified compatriot. Organizational Behavior and Human Decision Processes, 104, 150-157. doi:10.1016/j.obhdp.2007.04.006

Kraus, M. W., \& Keltner, D. (2013). Social class rank, essentialism, and punitive judgment. Journal of Personality and Social Psychology, 105, 247-261. doi: 10.1037/a0032895

Lakens, D., \& Evers, E. R. K. (2014). Sailing from the seas of chaos into the corridor of stability: Practical recommendations to increase the informational value of studies. Perspectives on Psychological Science, 9, 278-292. doi: 10.1177/1745691614528520

Leslie, S. J. (2013). Essence and natural kinds: When science meets preschooler intuition. In 
T. S. Gendler \& J. P. Hawthorne (Eds.), Oxford studies in epistemology (pp. 108-165). Oxford, UK: Oxford University Press.

Mandalaywala, T. M., Amodio, D., \& Rhodes, M. (2018). Essentialism promotes racial prejudice by increasing endorsement of social hierarchies. Social Psychological and Personality Science, 9, 461-469. doi: 10.1177/1948550617707020

Mandalaywala, T. M., Ranger-Murdock, G., Amodio, D. M., \& Rhodes, M. (In press). The nature and consequences of essentialist beliefs about race in early childhood. Child Development.

Medin, D. L., \& Ortony, A. (1989). Psychological essentialism. In S. Vosniadou \& A. Ortony (Eds.), Similarity and analogical reasoning (pp. 179-195). New York, NY: Cambridge University Press.

Mededovic, J. (2017). The profile of a criminal offender depicted by HEXACO personality traits. Personality and Individual Differences, 107, 159-163. doi: 10.1016/j.paid.2016.11.015

Meyer, M., Leslie, S. J., Gelman, S. A., \& Stilwell, S. M. (2013). Essentialist beliefs about body transplants in the United States and India. Cognitive Science, 37, 668-710. doi: $10.1111 / \operatorname{cogs} .12023$

Montoya, A. K., \& Hayes, A. F. (2017). Two-condition within-participant statistical mediation analysis: A path-analytic framework. Psychological Methods, 22, 6-27. doi: $10.1037 /$ met0000086

Newman, G. E., Bloom, P., \& Knobe, J. (2014). Value judgments and the true self. Personality and Social Psychology Bulletin, 40, 203-216. doi: 10.1177/0146167213508791

Pauker, K., Apfelbaum, E. P., \& Ambady, N. (2010). Race salience and essentialist thinking in 
racial stereotype development. Child Development, 81, 1799-1813. doi:

10.1111/j.1467-8624.2010.01511.x

Prentice, D. A., \& Miller, D. T. (2006). Essentializing differences between women and men. Psychological Science, 17, 129-135. doi: 10.1111/j.1467-9280.2006.01675.x

Raine, A. (2013). The anatomy of violence: The biological roots of crime. New York, NY: Pantheon Books.

Rhodes, M., Leslie, S. J., Saunders, K., Dunham, Y., \& Cimpian, A. (2018). How does social essentialism affect the development of inter-group relations? Developmental Science, 21, 1-15. doi: $10.1111 /$ desc. 12509

Rhodes, M., Leslie, S. J., \& Tworek, C. M. (2012). Cultural transmission of social essentialism. Proceedings of the National Academy of Sciences of the United States of America, 109, 13526-13531. doi: 10.1073/pnas. 1208951109

Rhodes, M., \& Mandalaywala, T. M. (2017). The development and developmental consequences of social essentialism. Wiley Interdisciplinary Reviews, 8, 1-18. doi: 10.1002/wcs. 1437

Roussos, G., \& Dunham, Y. (2016). The development of stereotype content: The use of warmth and competence in assessing social groups. Journal of Experimental Child Psychology, 141, 133-144. doi: 10.1016/j.jecp.2015.08.009

Schmider, E., Ziegler, M., Danay, E., Beyer, L., \& Buhner, M. (2010). Is it really robust? Reinvestigating the robustness of ANOVA against violations of the normal distribution assumption. Methodology, 6, 147-151. doi: 10.1027/1614-2241/a000016

Segall, G., Birnbaum, D., Deeb, I., \& Diesendruck, G. (2015). The intergenerational transmission 
of ethnic essentialism: How parents talk counts the most. Developmental Science, 18, 543-555. doi:10.1111/desc. 12235

Simmons, J., Nelson, L., \& Simonsohn, U. (2013). Life after p-hacking. Paper presented at the annual meeting of the Society for Personality and Social Psychology. New Orleans, LA.

Smith, C. E., \& Warneken, F. (2016). Children's reasoning about distributive and retributive justice across development. Developmental Psychology, 52, 613-628. doi: $10.1037 / \mathrm{a} 0040069$

Sousa, P., Atran, S., \& Medin, D. (2002). Essentialism and folkbiology: Evidence from Brazil. Journal of Cognition and Culture, 2, 195-223. doi: 10.1163/15685370260225099

Starmans, C., \& Bloom, P. (2016). When the spirit is willing, but the flesh is weak: Developmental differences in judgments about inner moral conflict. Psychological Science, 27, 1498-1506. doi: 10.1177/0956797616665813

Strohminger, N. \& Nichols, S. (2014). The essential moral self. Cognition, 131, 159-171. doi: 10.1016/j.cognition.2013.12.005

Tasimi, A., Gelman, S. A., Cimpian, A., \& Knobe, J. (2017). Differences in the evaluation of generic statements about human and non-human categories. Cognitive Science, 41, 19341957. doi: $10.1111 / \operatorname{cogs} .12440$

Taylor, M. G., Rhodes, M. \& Gelman, S. A. (2009). Boy wills be boys, cows will be cows: Children's essentialist reasoning about gender categories and animal species. Child Development, 80, 461-481. doi: 10.1111/j.1467-8624.2009.01272.x

Travis, J., Western, B., \& Redburn, S. (Eds.) (2014). The growth of incarceration in the United States: Exploring causes and consequences. Washington, DC: National Academies Press. 
Tsay, C., \& Banaji, M. R. (2011). Naturals and strivers: Preferences and beliefs about sources of achievement. Journal of Experimental Social Psychology, 47, 460-465. doi: 10.1016/j.jesp.2010.12.010

Waxman, S., Medin, D., \& Ross, N. (2007). Folkbiological reasoning from a cross-cultural developmental perspective: Early essentialist notions are shaped by cultural beliefs. Developmental Psychology, 43, 294-308. doi: 10.1037/0012-1649.43.2.294

Williams, M. J., \& Eberhardt, J. L. (2008). Biological conceptions of race and the motivation to cross racial boundaries. Journal of Personality and Social Psychology, 94, 1022-1047. doi: $10.1037 / 0022-3514.94 .6 .1033$

Zelazo, P. D., Helwig, C. C., \& Lau, A. (1996). Intention, act, and outcome in behavioral prediction and moral judgment. Child Development, 67, 2478-2492. doi: $10.2307 / 1131635$ 


\section{Appendix: Self-Relevant Essentialism Questions}

$*=$ reverse scored item

Do you think that you are a good person?

*Why are you a good person? Is it because of things that people around you did?

In the future, will scientists be able to figure out if you are a good person by looking at your

blood under an x-ray or microscope?

Some other people are NOT good people. Do you think that your brain is different from the brain of someone who is NOT a good person?

Do you think that you were born a good person?

Do you think that you have always been a good person?

*Do you think that you can change whether or not you're a good person if you want to? 